\title{
REFLEXÕES PARA A EPISTEMOLOGIA EM GEOGRAFIA ATRAVÉS DA OBRA DE WALTER BENJAMIN: LUGAR E EXPERIÊNCIA
}

\author{
Ana Carolina Colnago Roco de Azevedo, Bruno Leonardo Galdino de Azevedo \\ Universidade Estadual Paulista - UNESP, Programa de Pós Graduação em Educação, Presidente Prudente, SP. E-mail: \\ carolcolnago@gmail.com, professorbrunoazevedo@gmail.com. \\ Bolsista pela Coordenação de Aperfeiçoamento de Pessoal de Nível Superior (CAPES).
}

\section{RESUMO}

O presente artigo é resultado de pesquisa desenvolvida ao longo do ano de 2018 no âmbito dos estudos relativos à Filosofia da Educação, o qual tem como objetivo articular alguns escritos do filósofo Walter Benjamin com a categorização de lugar. Para isso, realizou-se um estudo de caráter bibliográfico em que buscou-se investigar a pertinência e relevância dos escritos do filósofo no que tange à descrição e apropriação espacial que permeiam as narrativas: "Obras Escolhidas volume 2: Rua de Mão Única", "Obras Escolhidas volume 3: Charles Baudelaire: Um Lírico no Auge do Capitalismo". Ao término da pesquisa, concluiu-se que os excertos analisados na obra benjaminiana reafirmam a pertinência de agregar o conceito de experiência, memória e as percepções espaciais como elementos atinentes à produção da Geografia Cultural.

Palavras-chave: Walter Benjamin; Experiência; Memória; Lugar; Geografia Cultural.

\section{REFLECTIONS FOR EPISTEMOLOGY IN GEOGRAPHY THROUGH THE WORK OF WALTER BENJAMIN: PLACE AND EXPERIENCE}

\begin{abstract}
The present article is a result of research developed during the year 2018 in the scope of studies related to the Philosophy of Education. In this way, the objective was to articulate the writings of the philosopher Walter Benjamin with the categorization of place. For this, a study of bibliographical character was carried out in the scope of the qualitative research, in which it was investigated the pertinence and relevance of the philosopher's writings regarding the description and spatial appropriation that permeate the narratives: "Obras Escolhidas volume 2: Rua de Mão Única", "Obras Escolhidas volume 3: Charles Baudelaire: Um Lírico no Auge do Capitalismo". At the end of the research, it was concluded that the excerpts analyzed in Benjamin's work reaffirm the pertinence of adding the concept of experience, memory and spatial perceptions as elements related to the production of Cultural Geography.
\end{abstract}

Keywords: Walter Benjamin; Experience; Memory; Place; Cultural Geography. 


\section{INTRODUÇÃO}

O presente artigo visa sintetizar o resultado de pesquisa proveniente dos estudos desenvolvidos no ano de 2018 no campo da Filosofia da Educação. Isto posto, parte-se da noção de experiência para, então, adentrar os meandros da obra de Walter Benjamin.

Em filosofia, experiência diz respeito ao conhecimento difundido pelos sentidos, a assimilação sensível da exterioridade, cuja possibilidade de confirmação ou refutação é empírica. Também pode ser concebida em caráter interno como fato de viver algo dado anteriormente a toda reflexão (MEINERZ, 2008).

O conceito de experiência aparece na obra do filósofo Walter Benjamin entrelaçada ao corpo e aos sentidos que dele provém e relaciona-se com a memória, com aquilo que é passado através das gerações, que tem o peso da tradição e que, por se situar no âmbito da transmissão geracional, nos permite relacionar o ato de transmitir como um ato educativo, formativo, ou seja, nesta compreensão, localiza-se o cerne da formação humana (LESSA, 2016).

Tuan (2013) retoma a experiência no âmbito da Geografia Cultural, entendendo-a como as diferentes maneiras que possibilitam ao indivíduo conhecer e construir a realidade. Estas apropriações podem variar desde os sentidos mais diretos e passivos como o olfato, paladar e tato, até a ativa percepção visual e a indireta maneira de simbolização. Nesta perspectiva, as emoções proporcionam um colorido a toda experiência humana, o que inclui os extratos mais elevados do pensamento. Volta-se, ainda, para o mundo exterior, pois ver e pensar claramente vão além do eu. O autor retoma, também, a etimologia da palavra experiência que "provém da mesma raiz latina (per) de "experimento", "experto", e "perigoso". Para experienciar no sentido ativo, é necessário aventurar-se no desconhecido e experimentar o ilusório e o incerto" (TUAN, 2013, p. 18).

Dessa forma, objetiva-se pensar uma Geografia que permeie as experiências, a utilização dos sentidos na construção de uma percepção sobre o espaço, retomando a noção da corporeidade como pressuposto central, protagonista do movimento de reconhecimento dos objetos e diferentes meios e da criação de vínculos afetivos, articulando os aforismos de Walter Benjamin com a categoria lugar, embasando uma perspectiva filosófica e geográfica.

\section{METODOLOGIA}

Constituiu-se como viés metodológico do trabalho desenvolvido a pesquisa de tipo qualitativa e, mais especificamente, bibliográfica. Chizzotti (2003, p. 221) aponta que: "O termo qualitativo implica uma partilha densa com pessoas, fatos e locais que constituem objetos de pesquisa, para extrair desse convívio os significados visíveis e latentes que somente são perceptíveis a uma atenção sensível".

Para alcançar os objetivos propostos foram analisados os textos Infância em Berlim e $O$ Flâneur que integram as seguintes obras de Walter Benjamin: "Obras Escolhidas volume 2: Rua de Mão Única" (2012)"; "Obras Escolhidas volume 3: Charles Baudelaire: Um Lírico no Auge do Capitalismo" (2010). A partir das leituras e discussões buscou-se uma articulação dos conceitos extraídos das obras referentes à experiência, memória e lugar com apontamentos da Geografia Cultural, através dos escritos de Tuan (2013), e das investigações conduzidas por Santos (2002), Ferraz (2005), Vaz (2010), Gaeta (2012) e Lessa (2016).

\section{RESULTADOS}

A partir do levantamento bibliográfico e da leitura hermenêutica realizada ao longo da pesquisa, infere-se que há na obra do filósofo Walter Benjamin um vasto material que se mostra profícuo para a apropriação em diversas áreas, entre elas, a Geografia. A escrita do autor, além de filosófica, agrega elementos da sociologia, da literatura (algo que aparece nitidamente em sua 
análise sobre Baudelaire), e das percepções concernentes ao espaço, que "transforma-se em lugar à medida em que adquire definição e significado" (TUAN, 2013, p. 167).

Parte-se, então, para o entendimento de analisar os excertos de Benjamin à luz da categoria de lugar, pois a espacialização ali presente articula-se às experiências íntimas, mesclando o sujeito, sua soma de afetos e os lugares a ele conectados. Segundo Tuan "Alcança-se a identidade do lugar pela dramatização das aspirações, necessidades e ritmos funcionais da vida pessoal e dos grupos" (p. 217).

A aproximação da obra de Walter Benjamin com a Geografia Cultural contemporânea, torna-se possível, pois, as categorias de lugar, território, espaço vivido, entre outras, estão relacionadas com as impressões individuais constituídas a partir da apreensão espacial. Entretanto, não se trata de uma redenção do espaço que se resume apenas ao indivíduo ou que nele tem um fim, mas o resgate do espaço de todos, da memória coletiva. O indivíduo, nesta perspectiva, constrói o elo entre a memória pretérita e o tempo presente (SANTOS, 2002).

O exercício de aproximar dois autores que não se situam na mesma temporalidade e que se notabilizaram por escritos em áreas distintas mostra-se sempre como desafio, entretanto, buscar tal associação faz parte do projeto de realizar o conhecimento científico de maneira transdisciplinar, visando romper com a rigidez do pensamento que se engaveta. Walter Benjamin e Yi-Fu-Tuan mesclam, em suas narrativas fluídas, uma interpretação dinâmica dos elementos espaciais, temporais, sociais e artísticos, possibilitando por meio de ramificações a convergência de seus trabalhos.

\section{DISCUSSÃO}

As concepções de Walter Benjamin concernentes ao mundo urbano, em especial da Paris moderna do século XIX, aparecem como retratos da época de ambientes particulares. Trata-se de observar a sedimentação do mundo de exagerada mercantilização, apontar o conflito entre a singularidade do ser e a massificação capitalista, destacar a manifestação moderna do drama do homem em sua tentativa de transcender a dimensão material-temporal e encontrar sentido diante da morte e destruição. São mundos mercantis, existenciais e culturais (GAETA, 2012, p. 401).

Segundo Vaz (2010), encontramos nos escritos de Benjamin as cidades em quatro registros, como pesquisa literária e sócio-histórica, sobretudo sobre a cidade de Paris, além de Londres e Moscou, na qual se mesclam a experiência urbana do autor, a exegese e a livre interpretação dos seus grandes escritores, especialmente Baudelaire; o trabalho da memória, nos complexos aforismos sobre Berlim, no qual se vê o exercício de deliberadamente, ou não, lembrar e esquecer ; o relato de viagem, quando encontramos as ilhas e cidades litorâneas italianas, como Capri e Nápoles; e o diário pessoal e intransferível sobre Moscou.

Para Vaz (2010) cidade é expressão de uma experiência moderna, na qual o corpo é um personagem da urbanização. A cidade, é ainda, o lugar das novas configurações sensoriais determinadas por um predomínio quase que absoluto do olhar sobre os outros sentidos. Assim, "se é na cidade que a Modernidade encontra seu destino, e é na recordação que a narrativa faz preservar a esperança de salvação, então, é preciso que se pensem as singularidades da história e da memória" (VAZ, 2010).

Gaeta (2012), em seus estudos sobre Walter Benjamin, caracteriza o urbano para além da aglomeração de pessoas e edificações "A cidade (ou seus elementos, como as passagens) é, por assim dizer, materialização da linguagem do inconsciente, espacialização da estrutura onírica, materialização do imaginário" (p. 47).

Ferraz (2005) retoma o debate acerca da cidade e do exercício de percebê-la por meio dos diversos sentidos e significados, o que requer olhá-la a partir de outro prisma, como no jogo da criança no armário, há de se desvendar e experimentar o mundo como mistério e 
deslumbramento. Ou como um viajante que ao percorrer terras estranhas, identifica, por analogias e comparações com suas memórias, experiências e informações, desvenda novas perspectivas, os significados ocultos ou esquecidos dos lugares e nomes que percorre e experimenta. O que se complementa a partir da perspectiva de Tuan, na qual: "A cidade é um lugar, um centro de significados, por excelência. Possui muitos símbolos bem visíveis. Mais ainda, a própria cidade é um símbolo (2013, p. 211).

Em sua análise acerca da cidade, Benjamin recorre a um esquadrinhamento do ambiente urbano, os quais se materializam nas ruas que abrigam as diferentes edificações. "As ruas são a memória do coletivo. O coletivo é um ser eternamente inquieto, eternamente agitado, que, entre os muros dos prédios, vive, experimenta, reconhece e inventa tanto quando os indivíduos ao abrigo de suas quatro paredes" (BENJAMIN, 2010, p. 194).

Destarte, observam-se nestes trechos que a acepção de lugar se constitui como parte do emaranhado filosófico presente nos escritos Benjaminianos, que ao mergulhar na particularidade das coisas e lugares, reafirma o lugar experimentado, que vai desde cômodos de sua residência, até a cidade total.

Isto posto, tem-se a presença do flâneur ${ }^{1}$ como sujeito que representa a modernidade e desfruta dos aspectos da cidade: "Aquela embriaguez anamnéstica em que vagueia o flâneur pela cidade não se nutre apenas daquilo que, sensorialmente, lhe atinge o olhar; com frequência também se apossa do simples saber, ou seja, de dados mortos, como de algo experimentado e vivido (BENJAMIN, 2010, p. 186).

Uma embriaguez acomete aquele que longamente vagou sem rumo pelas ruas. A cada passo, o andar ganha uma potência crescente; sempre menor se torna a sedução das lojas, dos bistrôs, das mulheres sorridentes e sempre mais irresistível o magnetismo da próxima esquina, de uma massa de folhas distantes, de um nome de rua. Então vem a fome. Mas ele não quer saber das mil e uma maneiras de aplacá-la. Como um animal ascético, vagueia através de bairros desconhecidos até que, no mais profundo esgotamento, afunda em seu quarto, que o recebe estranho e frio (BENJAMIN, 2010, p. 186).

Quando rememora as suas memórias de criança, sobretudo em sua obra sobre a Infância em Berlim, Benjamin ressalta os gestos, sons, cheiros, a flexibilidade ou rigidez dos materiais que compõem os objetos e sua relação com o tato do indivíduo, deixando marcas físicas e afetivas, construindo a partir dessas múltiplas percepções nuances da subjetividade de ser sujeito no mundo.

O espaço tem sentido temporal nas reflexões do poeta, no enigma da exploração, no drama da migração e na representação das experiências pessoais do cotidiano. A própria linguagem revela a íntima conexão entre pessoa, espaço e tempo (TUAN, 2013, p. 156).

Às vezes minha mãe me levava para fazer compras em tardes de inverno. Era uma Berlim escura e desconhecida que, à luz de gás, se estendia à minha frente. Ficávamos no antigo Oeste, cujos arruamentos eram mais uniformes e despretensiosos que os preferidos posteriormente. Àquela hora já não se podia perceber com clareza as sacadas e as colunas, mas nas fachadas havia luz. Fosse por causa das cortinas de musselina, fosse por causa das venezianas ou da camisa da lâmpada de gás suspensa, aquela luz pouco revelava dos aposentos iluminados. Não tinha a ver com nada, a não ser consigo mesma. Atraía-me e me deixava pensativo. Ainda hoje isso me acontece na memória. E é assim que sou conduzido a um de meus cartões postais. Este exibia uma praça em Berlim. As casas que a rodeavam eram de um azul delicado; o céu noturno no qual pairava a Lua, de um azul mais escuro. Não haviam colorido nem a Lua nem as janelas na camada azul do cartão. Era preciso colocá-las contra a luz, o que fazia emanar das nuvens e da série de janelas um súbito clarão amarelado. Eu não conhecia a paisagem representada. Abaixo

\footnotetext{
${ }^{1}$ Segundo Rouanet (1992, p. 50), o flâneur se caracteriza como o "detentor de todas as significações urbanas, do saber integral da cidade, do seu perto e do seu longe, do seu presente e do seu passado".
} 
estava inscrito "Porta de Halle". Porta e átrio nela se mesclavam, formando a gruta iluminada na qual encontro a lembrança da Berlim hibernal (BENJAMIN, 2012, p.127).

Segundo Vaz (2010), há ainda na obra Infância em Berlim um resgate da experiência vivida, entre memória e esquecimento e a experiência presente, do adulto que conserva e perlabora a textura de sua própria infância.

Observa-se, ainda, como peculiaridade das narrativas benjaminianas, a dimensão estética da linguagem, que faz com que se possa captar uma leitura além da narrativa, aguçando sentidos e emanando afetos de literalidade, não se trata de licença poética, mas de uma poiesis que fala.

Em nosso jardim havia um pavilhão abandonado e carcomido. Gostava dele por causa de suas janelas coloridas. Quando, em seu interior, passava a mão de um vidro para outro, ia me transformando. Tingia-me de acordo com a paisagem na janela, que se apresentava ora chamejante, ora empoeirada, ora esmaecida, ora suntuosa. Acontecia o mesmo com minhas aquarelas, onde as coisas me abriam seu regaço tão logo as tocava com uma nuvem úmida. Coisa semelhante se dava com as bolhas de sabão. Viajava dentro delas por todo o recinto e misturava-me ao jogo de cores de suas cúpulas até que se rompessem [...] (BENJAMIN, 2012, p. 101).

Neste viés, o infantil aparece com a potência de conectar o particular ao que é universal e, ainda, como um portal de segurança, em que o ameaçador passa a ser apaziguado, com a imaginação construindo uma vertente de resistência.

Ao se discutir o denominado espaço experiencial faz-se necessário introduzir os objetos e os lugares que definem o espaço, o espaço da criança se amplia e torna-se mais articulado à medida em que ela reconhece e atinge mais objetos, e lugares permanentes, transformando o que outrora era espaço em lugar, por meio de seus aspectos familiares (TUAN, 2013).

\section{CONSIDERAÇÕES FINAIS}

Por meio da análise conduzida ao longo deste trabalho, intencionamos a realização de um caminho inverso no que tange à cronologia do indivíduo que experimenta a cidade, tal exercício justifica-se pela tentativa de olhar para o lugar da maneira como faz a criança, que com curiosidade e potencialização dos afetos, torna maleável a rigidez que embrutece os espaços urbanos, muitas vezes cinzentos e impessoais.

Assim como propõe Tuan (2013), a estrutura e o tom sentimental do espaço estão unidos à experiência, ao temperamento e propósito do indivíduo. Nós adquirimos conhecimento do mundo através das possibilidades e limitações dos nossos sentidos. Assim, o espaço que podemos perceber estende-se na frente e ao redor de nós, dividindo-se em regiões de qualidades e percepções diversas.

Por conseguinte, através desta perspectiva buscou-se articular a filosofia de Walter Benjamin e a força de suas narrativas com conceitos atinentes à Geografia Cultural, que acreditamos ser construída a partir da experiência, da memória e da relação do homem com o lugar que habita, e que por ele é habitado.

\section{REFERÊNCIAS}

BENJAMIN, W. Charles Baudelaire: Um lírico no auge do capitalismo. Obras Escolhidas v. 3. 1a Ed. São Paulo: Brasiliense, 2010.

. Rua de Mão Única. Obras Escolhidas v. 2. 5ạ Ed. São Paulo: Brasiliense, 2012.

CHIZZOTTI, A. A pesquisa qualitativa em ciências humanas e sociais: evolução e desafios. Revista Portuguesa de Educação, Braga, n 16, v. 2, p. 221-236, 2003. 
FERRAZ, C. B. O. Walter Benjamin: seu pensamento e a geografia. In: X Encontro de Geógrafos da América Latina -2005, São Paulo, SP - Universidade de São Paulo. Anais (on-line). São Paulo: 2005. Disponível

em: http://observatoriogeograficoamericalatina.org.mx/egal10/Teoriaymetodo/Pensamientogeografic o/03.pdf. Acesso em: 07/2018.

GAETA, A. C. Paris dos espelhos em Walter Benjamin. São Paulo: Cultura Acadêmica, 2012.

LESSA, J. S. O conceito de experiência em Walter Benjamin: elementos para pensar a educação na infância. Zero-a-seis, Florianópolis, v. 18, n. 33, p.108-121. jan-jun/2016.

MEINERZ, A. Concepção de Experiência em Walter Benjamin. Dissertação (Mestrado em Filosofia). Porto Alegre: Universidade Federal do Rio Grande do Sul, 2008.

ROUANET, S. P. A cidade que habitam os homens ou são eles que moram nela. História material em Walter Benjamin “trabalho das passagens". Revista da USP. São Paulo, 1992.

SANTOS, G. R. dos. Espaço e experiência em Walter Benjamin. Boletim Goiano de Geografia, Goiânia, v.22, n. 02, p. 199-205. jul-dez/2002.

TUAN, Y. F. Espaço e Lugar: a perspectiva da experiência. Londrina: EDUEL, 2013.

VAZ, A. F. Educação, experiência, sentidos do corpo e da infância (um estudo experimental em escritos de Walter Benjamin). In: PAGNI, Pedro Angelo; GELAMO, Rodrigo Pelloso (Orgs.). Experiência, educação e contemporaneidade. Marília, SP: Poesis, p. 35-48,

2010. 